\title{
EFFECT OF GENETIC MODIFICATION OF MAIZE PLANT ON PHARMACEUTICALLY IMPORTANT PROPERTIES OF ITS STARCH
}

\author{
LATEEF GBENGA BAKRE ${ }^{1}$, OLUBUNMI JUMOKE OLAYEMI ${ }^{*}$, ADERINSOLA DUPE \\ ADEGBESAN ${ }^{1}$, OLUYEMISI ADEBOWALE BAMIRO ${ }^{1}$ AND OLOBAYO OLUFUNSHO \\ KUNLE $^{2}$ \\ 1Department of Pharmaceutics and Pharmaceutical Technology, Faculty of Pharmacy, \\ Olabisi Onabanjo University, Sagamu, Nigeria \\ ${ }^{2}$ Department of Pharmaceutical Technology and Raw Materials Research, National \\ Institute for Pharmaceutical Research and Development, Abuja, Nigeria
}

Published online: 23 November 2021

To cite this article: LATEEF GBENGA BAKRE, OLUBUNMI JUMOKE OLAYEMI, ADERINSOLA DUPE ADEGBESAN, OLUYEMISI ADEBOWALE BAMIRO \& OLOBAYO OLUFUNSHO KUNLE (2021) Effect of genetic modification of maize plant on pharmaceutically important properties of its starch, Malaysian Journal of Pharmaceutical Sciences, 19(2): 61-72. https://doi.org/10.21315/mjps2021.19.2.4

To link to this article: https://doi.org/10.21315/mjps2021.19.2.4

\begin{abstract}
Genetic engineering of maize plants for improved yield, drought and pest resistance has received considerable attention in agricultural research. The aim of this work is to determine the effect of genetic modification of maize plant on some pharmaceutically relevant fundamental properties of its isolated starches. Properties of starches isolated from PVA 39 and IWD 15 maize genotypes were compared with starch from unmodified maize grains. Morphology studied by scanning electron microscopy (SEM), Fourier transform infrared (FTIR) spectroscopy and differential scanning calorimetry (DSC) were evaluated. Swelling capacity, amylose content, pasting behaviour of the starches were also determined. SEM revealed that all the starches are largely irregular and polygonal with few round shaped granules. FTIR showed identical peaks in all the starch samples and DSC revealed higher enthalpies of starch gelatinisation from the modified grains. Modification also increased amylose content, swelling capacity and viscosity of the starches. Genetic modification increased amylose content which positively affected pharmaceutically important properties like moisture sorption and viscosity, thus, increasing their value in formulations especially as binders.
\end{abstract}

Keywords: Amylose content, Genetic modification, Maize starch, Pharmaceutical properties, Swelling capacity

"Corresponding author: olubunmibiala@yahoo.co.uk

(c) Penerbit Universiti Sains Malaysia, 2021. This work is licensed under the terms of the Creative Commons Attribution (CC BY) (http://creativecommons.org/licenses/by/4.0/). 


\section{INTRODUCTION}

Starch is a naturally occurring complex polysaccharide which is found as granules within plant cells and is semi-crystalline in nature (Singh et al. 2003). It is versatile and widely used in the manufacturing industry because it is relatively cheap and available, biodegradable, renewable and can be easily modified. It is very commonly used in the pharmaceutical industry as an excipient in the production of dosage forms, in its native and modified forms.

Starch properties are influenced by its botanical source, constituents and environmental conditions during cultivation. Since starch is composed mainly of amylose and amylopectin, their distribution within the starch granules influences its structure, chemical and physical properties (Zavareze and Dias 2011; Simsek et al. 2014). A lot of the pharmaceutical applications of starch is dependent on its swelling and flow behaviour in the presence of water. Studies have shown that these properties are largely dependent on the amylose/amylopectin ratio of the starch (Kunle 2019).

Despite its numerous potentials, starch in its native form is unstable when exposed to varying temperature and $\mathrm{pH}$, it has high tendency of retrogradation, limited solubility in common solvents and poor flow properties (Alcázar-Alay and Meireles 2015). These inherent properties limit its application especially for industrial purposes resulting in the need for modification.

Starch can be modified by physical, chemical, enzymatic and genetic methods (Yadav, Guleria and Yadav 2013). Genetic modification of starch can be achieved by transgene technology via targeting enzymes of starch biosynthesis. This molecular modification has significant effect on the physicochemical properties of starch (Ashok, Mather and Rajeesh 2016). Like other modification processes, genetic modification enhances the positive attributes of starch, increases its versatility and applicability. Reports of genetically modified cultivars resulting in the modification of their isolated starch have been documented. Regulation of a glycan enzyme in potatoes has been reported to modify the phosphorous content and viscosity of the isolated potato starch (Donath et al. 1998). High amylose potato starch has been obtained from potatoes grown by inhibition of branching enzymes (Schwall et al. 2000). Improved functional and molecular properties of starches isolated from some maize genotypes have also been documented (MilašinovićŠeremešić, Radosavljević and Dokić 2012).

Maize (Zea mays) is a major staple food grown all over the world particularly Asia, Latin America and Africa with diverse uses (Manu et al. 2019). Genetic engineering (breeding) of maize plant for improved yield, high starch and nutrient contents, enhanced tolerance to pest, drought, weed competition, heat stress, cold temperature stress and herbicides has received considerable attention in agricultural research. As part of these breeding programmes, the International Institute of Tropical Agriculture (IITA) in Nigeria has produced a pro-vitamin A-rich maize genotype (PVA 39) and drought resistance genotype (IWD 15).

The aim of this study is to determine the effect of genetic modification of maize plant on the pharmaceutically important physical properties of starches obtained from the cultivars (PVA 39 and IWD 15 genotypes).

Malay J Pharm Sci, Vol. 19, No. 2 (2021): 61-72 


\section{METHODS}

\section{Materials}

Unmodified maize grains and modified maize genotypes (IWD 15 and PVA 39) were obtained from International Institute of Tropical Agriculture, Nigeria. All other reagents used were of analytical grade.

\section{Extraction of Starch}

Starch was extracted from IWD 15 and PVA 39 and unmodified maize grains using an earlier method (Itiola and Odeku 2005). Grains of IWD 15 and PVA 39 and unmodified maize were washed with water to remove foreign materials. The washed grains were soaked in sodium metabisulphite solution $(0.75 \% \mathrm{w} / \mathrm{v})$ for $24 \mathrm{~h}$ and crushed using a blender. The starch dispersion was sieved using a calico cloth and left to stand at room temperature overnight. The supernatant was discarded and the sediment (starch) was washed with distilled water then air-dried for $24 \mathrm{~h}$. The dried starch then was pulverised in a mortar and coded as MI-15, MP-39 and NS for starches isolated from IWD 15, PVA 39 and the unmodified maize grains, respectively.

\section{Morphology}

Starch samples (NS, MI-15 and MP-39) were mounted on metal stubs, coated with gold and analysed using the scanning electron microscope (SEM) (ZEISS EVO18, Germany). Image resolutions of the starch surfaces were obtained at 1000 magnification at a current of $7 \mathrm{~mA}$ for 90 s (Bakre, Sarvaiya and Agrawal 2016).

\section{Fourier Transform Infrared (FTIR) Spectra Studies}

The starches (NS, MI-15 and MP-39) were triturated with potassium bromide, made into pellets $\left(1 \mathrm{ton} / \mathrm{cm}^{2}\right)$ and the infrared (IR) spectra was obtained between scanning ranges of $4000 \mathrm{~cm}^{-1}$ and $350 \mathrm{~cm}^{-1}$ using the (BX 273, Perkin-Elmer, USA). All the spectra were the average of 16 scans and were acquired at a resolution of $4 \mathrm{~cm}^{-1}$.

\section{Determination of Amylose Content}

The amylose content of the starches was determined using an earlier procedure (Man et al. 2014). Ten milligrams of dry starch were dispersed in $5.0 \mathrm{~mL}$ of dimethyl sulfoxide (DMSO) containing 10\% 6.0 M urea. Dissolution was obtained by incubating the mixture at $95^{\circ} \mathrm{C}$ for $1 \mathrm{~h}$ with intermittent vortexing. A $1.0 \mathrm{~mL}$ aliquot of the starch-DMSO solution was then placed in a $50 \mathrm{~mL}$ volumetric flask along with $45 \mathrm{~mL}$ of deionised water and $1.0 \mathrm{~mL}$ of iodine solution was added. The mixture was made up to $50 \mathrm{~mL}$ with deionised water, mixed immediately and placed in darkness for $20 \mathrm{~min}$. Control solution was made in the same way but without sample. All samples were scanned from $400 \mathrm{~nm}$ to $900 \mathrm{~nm}$ with a spectrophotometer (Ultrospec 6300 pro, Amershan Biosciences). Apparent amylose content (AAC) was evaluated from absorbance at $620 \mathrm{~nm}$. The recorded values were converted to percent of amylose by reference to a standard curve prepared with amylopectin and amylose. The experiment was performed in duplicate. 


\section{Determination of Swelling Capacity}

Swelling index was determined using the method of (Bakre, Osideko and Bamiro 2017). A $5 \% \mathrm{w} / \mathrm{v}$ dispersion of starch prepared in a $100 \mathrm{~mL}$ graduated cylinder was allowed to stand for $24 \mathrm{~h}$ and the swelling capacity was calculated.

\section{Determination of Moisture Content}

The moisture content of the starches (NS, Ml-15 and MP-39) were obtained by gravimetric analysis using standard procedure (British Pharmacopoeia 2013).

\section{Gelatinisation Temperature}

This was determined using a differential scanning calorimeter (DSC1, Toledo, USA). The starch samples were placed in the aluminum pans of the equipment and scanned between $60^{\circ} \mathrm{C}$ and $300^{\circ} \mathrm{C}$ at a heating rate of $20 \mathrm{~mL} / \mathrm{min}$ under inert nitrogen flow (Sanyang et al. 2015).

\section{Determination of Pasting Properties}

The pasting properties were determined using a Rapid Visco-Analyzer (RVA, Serial-3, Newport Scientific, NSW, Australia). The method of Fan et al. 2016 was adopted. A $3 \mathrm{~g}$ quantity of starch was dispersed in $25 \mathrm{~mL}$ distilled water and heated using the following timetemperature schedules: holding at $50^{\circ} \mathrm{C}$ for $1 \mathrm{~min}$, heating to $95^{\circ} \mathrm{C}$ at $12^{\circ} \mathrm{C} / \mathrm{min}$, maintaining at $95^{\circ} \mathrm{C}$ for $2.5 \mathrm{~min}$, then cooling to $50^{\circ} \mathrm{C}$ at $12^{\circ} \mathrm{C} / \mathrm{min}$ and holding at $50^{\circ} \mathrm{C}$ for $1.4 \mathrm{~min}$. The final viscosity, peak viscosity, breakdown and setback viscosities were recorded.

\section{RESULTS AND DISCUSSION}

\section{Scanning Electron Microscopy}

The micrographs of the starch samples presented in Figure 1 reveal that all three samples are largely irregular and polygonal with few round shaped granules. Some compound granules with 2 to 3 units can also be identified. The results indicate that genetic modification (Figures 1a and 1b) had no effect on the shape and occurrence of starch granules in relation to the starch granules from the unmodified starch (Figure 1c). Similar observations have also been reported in the study of starch from genetically modified cassava roots (Wang et al. 2018).

\section{Fourier Transform}

The infrared spectra of the starch samples are presented in Figure 2. All the spectra show a broad rounded peak at $3281 \mathrm{~cm}^{-1}$ which represent the hydroxyl group, a sharp peak at $1640 \mathrm{~cm}^{-1}$ attributable to the tightly bonded water molecules and peaks at $1077 \mathrm{~cm}^{-1}$ which may be due to the stretching of the amorphous region of the starch. There was also a strong peak at $2928 \mathrm{~cm}^{-1}$ which is associated with the stretching mode of the amylopectin and amylose content of the starch. Bands around $900 \mathrm{~cm}^{-1}$ and below represent the unique fingerprint of starch (Surendra et al. 2014). Those observed around $3280 \mathrm{~cm}^{-1}$,

Malay J Pharm Sci, Vol. 19, No. 2 (2021): 61-72 
$3291 \mathrm{~cm}^{-1}$ and $3280 \mathrm{~cm}^{-1}$ in the spectra of unmodified starch, starch from IWD-15 and PVA-39, respectively, are indicative of $\mathrm{OH}$ stretching. Peaks observed at about $1640 \mathrm{~cm}^{-1}$, $1420 \mathrm{~cm}^{-1}$ and $1640 \mathrm{~cm}^{-1}$ for the three starches show the presence of intra-molecular hydrogen bonds, $\mathrm{C}-\mathrm{H}$ bending and $\mathrm{C}-\mathrm{O}$ stretching. Overall, there was no difference in the spectra of the starches which indicates that the genetic modification of the maize grain did not introduce any functional groups into the starch molecule.

\section{Amylose Content}

Amylose content is an essential characteristic that influences the physicochemical properties of starch. It is responsible for the swelling ability of starch; amylose molecules form lipid complexes which inhibit their leaching thus allowing the starch grains to swell (Singh et al. 2003). Amylose also influences starch solubility, gelling ability and gel strength once in contact with a liquid medium, these properties of starch makes it widely applicable for industrial processes (Campos, Gerschenson and Flores 2011). Table 1 shows that amylose content ranged between $29.4 \pm 0.12 \%$ and $45.2 \pm 0.11 \%$. Starch from MI-15 and MP-39 had appreciably higher amylose content than that from the unmodified maize $(29.4 \pm 0.12 \%)$ with MP-39 having the highest level $(45.2 \pm 0.12 \%)$. This suggests that starch from MP-39 would exhibit higher swelling capacity and better propensity to form gels. Both of these properties are important in determining the rate of drug release from a formulation.

Variations in amylose contents of starches extracted from bambara cultivars have been attributed it to the inherent genetic differences rather than the prevailing environmental conditions, since the different genotypes were grown in the same location (Kaptso et al. 2014). Genoytpic differences have also been determined to account for the main variation $(68 \%)$ in amylose contents of rice starches and not the differences in environmental conditions (Jing et al. 2010). The amylose content of isolated starches from maize cultivars in this study falls within the range of values previously reported for pulse starches such as cowpea and pigeon pea (Hoover et al. 2010).

\section{Swelling Index}

Swelling is an indication of the ability of starch granules to absorb water and the extent of hydration and water retention. This is responsible for the structural transition within the granules which influences drug release from a formulation via diffusion, erosion or the combination of both mechanisms (Omidian and Park 2008). Starch from MP-39 with the highest amylose content (Table 1) had the highest swelling index (3.91). This confirms the observation of Yoon and Kinam (2004) that the swelling of starch during heating is a function of the level of interaction between starch chains within the amorphous and crystalline regions which depends on the amylose content. However, Ml-15 which has a higher amylose content than the native starch exhibited a lower swelling index. This may be due to chain scission in Ml-15 which consequently affects the granule's ability to hold water. In addition, the ability of starch to swell is directly linked to amylopectin as such, high amylose content would reduce water uptake by the granules consequently decreasing its ability to swell (Singh et al. 2003; Muoki, Kinnear and Emmambux 2015). 


\section{Moisture Content}

Table 1 shows that all the starches had moisture content within the $15 \%$ official recommendation for starches (British Pharmacopoeia 2002). It is important to determine the presence of moisture in pharmaceutical materials because excessive moisture can influence the flow, mechanical properties and physical stability of drug formulations (Emeje, Isimi and Kunle 2008). Genetic modification does not have any effect on the moisture content of the starches.

Table 1: Some fundamental properties of the modified maize genotypes and unmodified maize grains.

\begin{tabular}{llll}
\hline Starch sample & Amylose content (\%) & Swelling index (\%) & Moisture content (\%) \\
\hline NS & $29.4 \pm 0.12$ & $1.69 \pm 0.01$ & $11.8 \pm 0.06$ \\
MI-15 & $35.0 \pm 0.11$ & $0.97 \pm 0.01$ & $12.1 \pm 0.09$ \\
MP-39 & $45.2 \pm 0.11$ & $3.91 \pm 0.02$ & $11.4 \pm 0.22$ \\
\hline
\end{tabular}

Notes: NS = starch from unmodified maize grains; MI-15 = starch from modified maize genotype IWD 15; MP-39= starch from modified maize genotype PVA 39

\section{Differential Scanning Calorimetry}

Differential scanning calorimetry (DSC) was used to determine the thermal behaviour of the starches when heated. The temperature at which gelatinisation occurs is influenced by the crystalline nature of the starch molecules and is an important property that influences their pharmaceutical application. Differences in gelatinisation temperature indicate differences in gel strength and this significantly influences the binding and compaction capabilities of starches (Vesterinen, Suortti \& Autio 2001).

Table 2 shows the gelatinisation temperatures: onset (To); peak (Tp); and end $\left(T_{e}\right)$, enthalpies of gelatinisation $\Delta \mathrm{H}\left(\mathrm{J} \cdot \mathrm{g}^{-1}\right)$ and peak height index $(\mathrm{PHI})$ of the three starches. Starches isolated from IVD 15 and PVA 39 had higher peak temperatures than NS. This can be attributed to their higher amylose content and crystalline nature as have been previously reported (Lindeboom, Chang and Tyler 2004).

Table 2: DSC parameters for starches from the modified maize genotypes and unmodified maize grains.

\begin{tabular}{llll}
\hline Thermal parameter & NS & MI-15 & MP-39 \\
\hline Onset temperature $\left(\mathrm{T}_{\circ}{ }^{\circ} \mathrm{C}\right)$ & 30.74 & 30.74 & 30.82 \\
Peak temperature $\left(\mathrm{T}_{\mathrm{p}}{ }^{\circ} \mathrm{C}\right)$ & 76.20 & 77.49 & 80.43 \\
End temperature $\left(\mathrm{T}_{\mathrm{e}}{ }^{\circ} \mathrm{C}\right)$ & 121.22 & 116.95 & 123.24 \\
Enthalpy of gelatinisation $\Delta \mathrm{H}\left(\mathrm{J} . \mathrm{g}^{-1}\right)$ & 346.99 & 631.30 & 457.72 \\
Peak height index $(\mathrm{PHI})$ & 7.63 & 13.50 & 9.23 \\
\hline
\end{tabular}

Notes: NS = starch from unmodified maize grains; MI-15 = starch from modified maize genotype IWD 15; MP-39= starch from modified maize genotype PVA 39

Malay J Pharm Sci, Vol. 19, No. 2 (2021): 61-72 
High amylose content is associated with increased granule strength and decreased mobility of amorphous chains (Akpa and Dagde 2012; Shah, Mewada and Mehta 2016) as such, higher temperatures would be required to cause gelatinisation of starches from the modified grains. However, the onset temperature of gelatinisation was similar for the three starches suggesting that gelatinisation could be initiated at the same temperature. Enthalpy of gelatinisation $(\Delta \mathrm{H})$ demonstrates the strength of the bond within the starch molecule which is broken on application of heat. The temperature range $(\Delta \mathrm{H})$ shows the different bond forces that is present within the starch granules (McPherson and Jane 1999). Higher enthalpies of gelatinisation observed with MP-15 and MP-39 show that higher energy is required to separate the bonds with the starch granules and suggests their application as better binders than NS in drug formulation. The low temperatures observed in NS shows its instability when exposed to varying temperature ranges as a result of weak molecular arrangement of the starch molecules.

\section{Pasting Behaviour}

The rheological properties of starch give insight into the mechanism by which gelatinisation takes place. Pasting occurs as a result of the process of gelatinisation of starches and it is associated with swelling of starch grains, leakage of granular contents and disruption of the granules (Atwell et al. 1988). Peak viscosity (PV) represents the highest viscosity reached by the gelatinised starch; it is a measure of the water binding ability of the granules and also indicates the ability of starch granules to swell before breakup (Rayan et al. 2015). Table 3 shows the peak viscosities of the starches were between $4259 \pm 146.37 \mathrm{~Pa}$-s and $4720 \pm$ 184.56 Pa-s.

Table 3: Pasting parameters of the modified maize genotypes and unmodified maize grains.

\begin{tabular}{llll}
\hline Pasting parameter & NS & MI-15 & MP-39 \\
\hline Peak viscosity (Pa-s) & $4507 \pm 121.62$ & $4720 \pm 184.56$ & $4259 \pm 146.37$ \\
Breakdown viscosity (Pa-s) & $2405 \pm 27.58$ & $1781 \pm 55.86$ & $2159 \pm 67.88$ \\
Final viscosity (Pa-s) & $2405 \pm 57.28$ & $4806 \pm 181.02$ & $3722 \pm 99.00$ \\
Setback viscosity (Pa-s) & $1548 \pm 91.92$ & $1867 \pm 52.33$ & $1673 \pm 20.51$ \\
Peak time (min) & $4.30 \pm 0.00$ & $4.80 \pm 0.00$ & $4.57 \pm 0.05$ \\
\hline
\end{tabular}

Notes: NS = starch from unmodified maize grains; MI-15 = starch from modified maize genotype IWD 15; MP-39= starch from modified maize genotype PVA 39

MI-15 exhibited the highest peak viscosity which suggests its ability to retain granule integrity after swelling indicated by its higher peak time $(4.80 \pm 0.00 \mathrm{~min})$. The differences in peak viscosity can be attributed to granular swelling ability of the individual starches. Final viscosity of the starch pastes was between $2405 \pm 57.28 \mathrm{~Pa}$-s and 4806 $\pm 181.02 \mathrm{~Pa}$-s; starches obtained from the IWD 15 and PVA 39 had higher final viscosity than NS with MI-15 having the highest value. Final viscosity has been reported to be due to the aggregation of amylose molecules (Blazek and Copeland 2008) resulting in greater hydrogen bond interactions, higher bond strength and increased viscosity. Although MP-39 had higher amylose content than MI-15, some studies have shown that there maybe other factors apart from amylose content that determine the viscosity of starch (Zeng et al. 1997; Black et al. 2000; Wickramasinghe et al. 2005; Majzoobi, Farahnaky and Amiri 2011). 
The setback viscosity represents re-crystallisation of the gelatinised starch during cooling. Starches isolated from the genotypes have higher setback viscosities in an order similar to that of final viscosity. The higher setback viscosity could be due to higher levels of amylose leached from the granules (Bakre, Ogun and Alayo 2014). It could also be attributed to a rearrangement reaction occurring between the amylose and amylopectin at lower temperatures leading to the increase in their final viscosities (Chen, Fu and Luo 2015). The breakdown viscosity which determines the extent of granule disintegration during stirring and heating and the stability of starch paste (Simi and Abraham, 2008) was lowered by the genetic modification. This effect was most pronounced in Ml-15. The parameters studied in Table 3 show that modification led to increased viscosity and higher resistance of starch granules to rupture. This suggests MP-15 and MP-39 will function as better binders than NS in solid dosage formulations.

\section{CONCLUSION}

This study has shown that genetic modification in maize cultivars IWD 15 and PVA 39 produced starches which have different properties from the native maize starch. The genetic modification had no effect on the shape of the granules and did not introduce new functional groups into the starch molecule. On the other hand, the modification produced starches with higher amylose content, better pasting properties and enthalpies of gelatinisation which suggests they may perform better as binding agents than starch from unmodified maize grains in pharmaceutical solid formulations than starch from unmodified maize grains.

\section{REFERENCES}

AKPA, J. G. \& DAGDE, K. K. (2012) Modification of cassava starch for industrial uses, International Journal of Engineering and Technology, 2: 913-919.

ALCÁZAR-ALAY, C. S. \& MEIRELES, M. A. A. (2015) Physicochemical properties, modifications and applications of starches from different botanical sources, Food Science Technology (Campinas), 35: 215-236. https://doi.org/10.1590/1678-457X.6749

ASHOK, A., MATHER, M. \& RAJEESH, C. R. (2016) Innovative value chain development of modified starch for a sustainable environment: A review, International Journal of Polymer Science Engineering, 2: 20-32.

ATWELL, W. A., HOOD, L. F., LINEBACK, D. R., VARRIANO-MARSTON, E. \& ZOBEL, H. F. (1988) The terminology and methodology associated with basic starch phenomena, Cereal Foods World, 33: 306-311.

BAKRE, L. G., OGUN, O. \& ALAYO, M. A. (2014) Influence of pregelatinization on the physicochemical and compressional characteristics of starches derived from two local varieties of Dioscorea rotundata, International Organization of Scientific Research (IOSR) Journal of Pharmacy, 4: 24-32. https://doi.org/10.9790/3013-040602024032

BAKRE, L. G., OSIDEKO, A. O. \& BAMIRO, O. A. (2017) Isolation and characterization of gum from Chrysophyllum albidum fruits as pharmaceutical excipient, Journal of Pharmaceutical Bioresearch, 14: 22-30. https://doi.org/10.4314/jpb.v14i1.3

Malay J Pharm Sci, Vol. 19, No. 2 (2021): 61-72 
BAKRE, L. G., SARVAIYA, J. I. \& AGRAWAL, Y. K. (2016) Synthesis, characterization and study of drug release properties of curcumin from polycaprolactone/organomodified montmorillonite nanocomposite, Journal of Pharmaceutical Innovation, 11: 300-307. https://doi.org/10.1007/s12247-016-9253-x

BLACK, C. K., PANOZZO, J. F., WRIGHT, C. L. \& LIM, P. C. (2000) Survey of white salted noodle quality characteristics in wheat landraces, Cereal Chemistry, 77: 468-472. https://doi.org/10.1094/CCHEM.2000.77.4.468

BLAZEK, J. \& COPELAND, L. (2008) Pasting and swelling properties of wheat flour and starch in relation to amylose content, Carbohydrate Polymers, 71: 380-387. https://doi.org/10.1016/j.carbpol.2007.06.010

BRITISH PHARMACOPOEIA. (2002) Her Majesty's Stationery Office: Volume I and II, (London, UK: University Press, Cambridge).

BRITISH PHARMACOPOEIA. (2013) Her Majesty's Stationery Office: Volume II, (London, UK: University Press, Cambridge).

CAMPOS, C. A., GERSCHENSON, L. N. \& FLORES, S. K. (2011) Development of edible films and coatings with antimicrobial activity, Food and Bioprocess Technology, 4: 849-875. https://doi.org/10.1007/s11947-010-0434-1

CHEN, H. M., FU, X. \& LUO, Z. G. (2015) Effect of gum arabic on freeze-thaw stability, pasting and rheological properties of tapioca starch and its derivatives, Food Hydrocolloids, 51: 355-360. https://doi.org/10.1016/j.foodhyd.2015.05.034

DONATH, H., AVTOMONOV, E. V., SARRAJE, I., VON DAHLEN, K. H., EL-ESSAWI, M. \& LORBERTH, J. (1998) Organoplatinum compounds VII. Trimethylplatinum fluoride $\left[\left(\mathrm{CH}_{3}\right)_{3} \mathrm{PtF}\right]_{4}$, the missing link in organoplatinum cluster chemistry: Its synthesis, crystal structure and a comparison to the crystal structure of $\left[\left(\mathrm{CH}_{3}\right)_{3} \mathrm{PtOH}\right]_{4}$, Journal of Organometallic Chemistry, 559: 191-196. https://doi.org/10.1016/S0022-328X(98)00481-1

EMEJE M, ISIMI C \& KUNLE O. (2008). Effect of Grewia gum on the mechanical properties of paracetamol tablet formulations, African Journal of Pharmacy and Pharmacology, 2: 1-6.

FAN, X., ZHANG, S., LIN, L., ZHAO, L., LIU, A. \& WEI, C. (2016) Properties of new starches from tubers of Arisaema elephas, Yunnanense and Erubescens, Food Hydrocolloids, 61: 183-190. https://doi.org/10.1016/j.foodhyd.2016.05.015

HOOVER, R., HUGHES, T., CHUNG, H. J. \& LIU, Q. (2010) Composition, molecular structure, properties, and modification of pulse starches: A review, Food Research International, 43: 399-413. https://doi.org/10.1016/j.foodres.2009.09.001

ITIOLA, O. A. \& ODEKU, O. A. (2005) Packing and cohesive properties of some locally extracted starches, Tropical Journal of Pharmaceutical Research, 4: 363-368. https://doi.org/10.4314/tjpr.v4i1.14621 
JING, Q., SPIERTZ, J. H. J., HENGSDIJK, H., KEULEN, H. V., CAO, W. \& DAI, T. (2010) Adaptation and performance of rice genotypes in tropical and subtropical environments, NJAS-Wageningen Journal of Life Sciences, 57: 149-157. https://doi.org/10.1016/j.njas.2010.04.002

KAPTSO, G. K., NJINTANG, Y. N., NGUEMTCHOUIN, M. M. G., SCHER, J., HOUNHOUIGAN, J. \& MBOFUNG, C. M. (2014) Physicochemical and micro-structural properties of flours, starch and proteins from two varieties of legumes: Bambara groundnut (Vigna subterranea), Journal of Food Science \& Technology, 52: 4915-4924. https://doi.org/10.1007/s13197-014-1580-7

KUNLE, O. O. (2019) Starch source and its impact on pharmaceutical applications, IN: M. EMEJE, (Ed.). Chemical properties of starch. pp. 1-14. (IntechOpen). http://doi.org/10.5772/intechopen.89811

LINDEBOOM, N., CHANG, P. R. \& TYLER, R. T. (2004) Analytical, biochemical and physicochemical aspects of starch granule size, with emphasis on small granule starch: A review, Starch/Starke, 56: 89-99. https://doi.org/10.1002/star.200300218

MAJZOOBI, M., FARAHNAKY, A. \& AMIRI, S. (2011) Physicochemical characteristics of starch component of wheat flours obtained from fourteen Iranian wheat cultivars, International Journal of Food Properties, 14: 685-696. https://doi.org/10.1080/10942910903367613

MAN, J., LIN, L., WANG, Z., WANG, Y., LIU, Q. \& WEI, C. (2014) Different structures of heterogeneous starch granules from high-amylose rice, Journal of Agricultural and Food Chemistry, 62: 11254-11263. https://doi.org/10.1021/jf503999r

MANU, N., OPIT, G. P., OSEKRE, E. A., ARTHUR, F. H., MBATA, G., ARMSTRONG, et al. (2019) Moisture content, insect pest infestation and mycotoxin levels of maize in markets in the northern region of Ghana, Journal of Stored Products Research, 80: 10-20. https://doi.org/10.1016/j.jspr.2018.10.007

MCPHERSON, A. E. \& JANE, J. (1999) Comparison of waxy potato with other root and tuber starches, Carbohydrate Polymers, 40: 57-70. https://doi.org/10.1016/S01448617(99)00039-9

MILAŠINOVIĆ-ŠEREMEŠIĆ, M. S., RADOSAVLJEVIĆ, M. M. \& DOKIĆ, L. P. (2012) Starch properties of various 'zp' maize genotypes, Acta Periodica Technologica (APTEFF), 43: 342. https://doi.org/10.2298/APT1243061M

MUOKI, P. N., KINNEAR, M. \& EMMAMBUX, M. N. (2015) Effect of the addition of soy flour on sensory quality of extrusion and conventionally cooked cassava complementary porridges, Journal of Sciences and Food Agriculture, 95: 730-738. https://doi.org/10.1002/jsfa.6820

OMIDIAN, H. \& PARK, K. (2008) Swelling agents and devices in oral drug delivery, Journal of Drug Delivery and Science Technology, 18(2): 83-93.

Malay J Pharm Sci, Vol. 19, No. 2 (2021): 61-72 
RAYAN, A. M., EL-SHAMEI, Z. S., SHATTA, A. A., GAB-ALLA, A. A. \& MOUSSA, E. A. (2015) Physicochemical properties of starch isolated from genetically modified corn (Ajeeb YG), Journal of Agroalimentary Processes and Technologies, 21: 53-66.

SANYANG, M. L., SAPUAN, S. M., JAWAID, M., ISHAK, M. R. \& SAHARI, J. (2015) Effect of plasticizer type and concentration on tensile, thermal and barrier properties of biodegradable films based on sugar palm (Arenga pinnata) starch, Polymers, 7: 11061124. https://doi.org/10.3390/polym7061106

SCHWALL, G. P., SAFFORD, R., WESTCOTT, R. J., JEFFCOAT, R., TAYAL, A. \& SHI, Y. C. (2000) Production of very-high-amylose potato starch by inhibition of SBE A and B, Nature Biotechnology, 18: 551-554. https://doi.org/10.1038/75427

SHAH, N., MEWADA, R. K. \& MEHTA, T. (2016) Crosslinking of starch and its effect on viscosity behavior, Review in Chemical Engineering, 32: 265-270. https://doi.org/10.1515/revce-2015-0047

SIMI, C. K. \& ABRAHAM, T. E. (2008) Physicochemical rheological and thermal properties of Njavara rice (Oryza sativa) starch, Journal of Agricultural and Food Chemistry, 56: 12105-12113. https://doi.org/10.1021/jf802572r

SIMSEK, S., MARTINEZ, M., DAGILOGLU, O., GUNNER, K. \& GECGEL, U. (2014) Physiochemical properties of starch from cereal based fermented food (Tarhana), Journal of Nutrition and Food Science, 4: 263-266.

SINGH, N., SINGH, J., KAUR, L., SODHI, N. S. \& GILL, B. S. (2003) Morphological, thermal and rheological properties of starches from different botanical sources, Food Chemistry, 81: 219-231. https://doi.org/10.1016/S0308-8146(02)00416-8

SURENDRA, A. B., PARIMALAVILLI, R., JAGANADHAM, K. \& SUDHAKARA, J. R. (2014) Chemical and structural properties of sweet potato starch treated with organic and inorganic acid, Journal of Food Science Technology, 1-9.

VESTERINEN, E., SUORTTI, T. \& AUTIO, K. (2001) Effects of preparation temperature on gelation properties and molecular structure of high-amylose maize starch, Cereal Chemistry, 78(4): 442-446.

WANG, W., HOSTETTLER, C. E., DAMBERGER, F. F., KOSSMANN, J., LLOYD, J. R. \& ZEEMAN, S. C. (2018) Modification of cassava root starch phosphorylation enhances starch functional properties, Frontier Plant Sciences, 9: 1-16. https://doi.org/10.3389/fpls.2018.01562

WICKRAMASINGHE, H. A. M., MIURA, H., YAMUCHI, H. \& NODA, T. (2005) Comparison of the starch properties of Japanese wheat varieties with those of popular commercial wheat classes from the USA, Canada and Australia, Food Chemistry, 93: 9-15. https://doi.org/10.1016/j.foodchem.2004.08.049 
YADAV, B. S., GULERIA, P. \& YADAV, R. B. (2013) Hydrothermal modification of Indian water chestnut starch: Influence of heat-moisture treatment and annealing on the physicochemical, gelatinization and pasting characteristics, LWT - Food Science and Technology (Campinas), 53: 211-217. https://doi.org/10.1016/j.Iwt.2013.02.007

YOON, Y. \& KINAM, P. (2004) Control of encapsulation efficiency and initial burst in polymeric microparticle systems, Archives of Pharmaceutical Research, 27: 1-12. https://doi.org/10.1007/BF02980037

ZAVAREZE, E. D. R. \& DIAS, A. (2011) Impact of heat moisture treatment and annealing in starches: A review, Carbohydrate Polymers, 83: 317-328. https://doi.org/10.1016/j.carbpol.2010.08.064

ZENG, M., MORIS, C. F., BATEY, I. L. \& WRIGLEY, C. W. (1997) Sources of variation for starch gelatinization, pasting, and gelation properties in wheat, Cereal Chemistry, 74: 63-71. https://doi.org/10.1094/CCHEM.1997.74.1.63 